\title{
ЛИМИТИРОВАНИЕ КРЕДИТНОЙ СДЕЛКИ КАК ИНСТРУМЕНТ СМЯГЧЕНИЯ ПОСЛЕДСТВИЙ НАРУШЕНИЯ ГРАНИЦ КРЕДИТА
}

\section{CREDIT TRANSACTION LIMITATION \\ AS A TOOL TO MITIGATE \\ THE CONSEQUENCES OF VIOLATION OF CREDIT BOUNDARIES}

\section{A. Ushanov}

Summary. This article is devoted to the analysis of the interdependence of the boundaries of credit at the micro level, on the one hand, and its essential characteristic - repayment, on the other. The theoretical aspects of the concept of "credit boundaries" are considered. The factors of violation of the boundaries of credit provided by banks to private and corporate clients are analyzed, resulting in the occurrence of overdue loans. It is noted that the current lending mechanism does not fully take into account the challenges of today. Based on the provision that the credit limit is a quantitative credit limit on the part of the lender, a mechanism for limiting corporate transactions is proposed, built on the hierarchy of the system of limits, the ultimate goal of which is to minimize the risks of non-repayment of the loan as the main indicator of violation of its boundaries.

Keywords: credit boundaries, Bank of Russia, consumer loans, credit boundaries, overdue debt, credit limits, hierarchy of limits.
B начале августа 2021 г. Федеральный фонд по защите прав вкладчиков и акционеров (далее Фонд) обратился в Банк России с целью решить проблему вложений в пирамиды заемных средств гражданами [1]. Речь шла о росте масштабов нецелевого потребительского кредитования, используемого гражданами на ведение предпринимательской деятельности.

Согласно действующему законодательству, нецелевой потребительский кредит может быть использован на любые цели, не связанные с предпринимательской деятельностью. В то же время, по оценкам экспертов, до 30\% средств, инвестируемых в пирамиды, приходится на кредиты. Вложение заемных средств в «пирамидальные» инвестпроекты, являющееся предпринимательской деятельностью, в масштабах больших, чем это необходимо для удовлетворения именно потребительских нужд, не только противоречит сущностному предназначению потребительского кредита, но и является проявлением нарушения его границ.

\author{
Ушанов Александр Евгеньевич \\ К.э.н., доцент, Финансовый университет при \\ Правительстве Российской Федерации, г. Москва \\ ushanov_0656@mail.ru
}

Аннотация. Данная статья посвящена анализу взаимозависимости границ кредита на микроуровне, с одной стороны, и его сущностной характеристики - возвратности, с другой. Рассмотрены теоретические аспекты понятия «границы кредита». Проанализированы факторы нарушения границ кредита, предоставляемого банками частным и корпоративным клиентам, результатом чего является возникновение просроченной задолженности по ссудам. Отмечено, что действующий механизм кредитования не в полной мере учитывает вызовы сегодняшнего дня. Основываясь на положении о том, что лимит кредитования является количественной границей кредита со стороны кредитора, предложен механизм лимитирования корпоративных сделок, построенный на иерархии системы лимитов, конечная цель которого - минимизации рисков невозврата кредита как основного индикатора нарушения его границ.

Ключевые слова: границы кредита, Банк России, потребительские кредиты, границы кредита, просроченная задолженность, лимиты кредитования, иерархия лимитов.

Нарушение границ потребительского кредита, как следствие его нецелевого использования, приводит к выхолащиванию самой сущности кредита как экономической категории - его возвратности, выражающейся в росте просроченных ссуд.

В широком понимании к аналогичным последствиям приводит рост объемов кредитования населения, опережающий рост его доходов. Чрезмерное относительно роста доходов населения стимулирование кредитования способно лишь краткосрочно оказать положительно влияние на экономику, но в перспективе - негативное.

В 3-м квартале 2021 г. зафиксирован резкий рост выдачи необеспеченных кредитов населению: увеличение по сравнению с аналогичным периодом прошлого года составило 36\%. По данным Банка России, общий кредитный портфель физических лиц в российских банках на 1.09.2021 г. составил 23,6 трлн. рублей, что на $24 \%$ больше, чем годом ранее, и на $2 \%$ выше показа- 


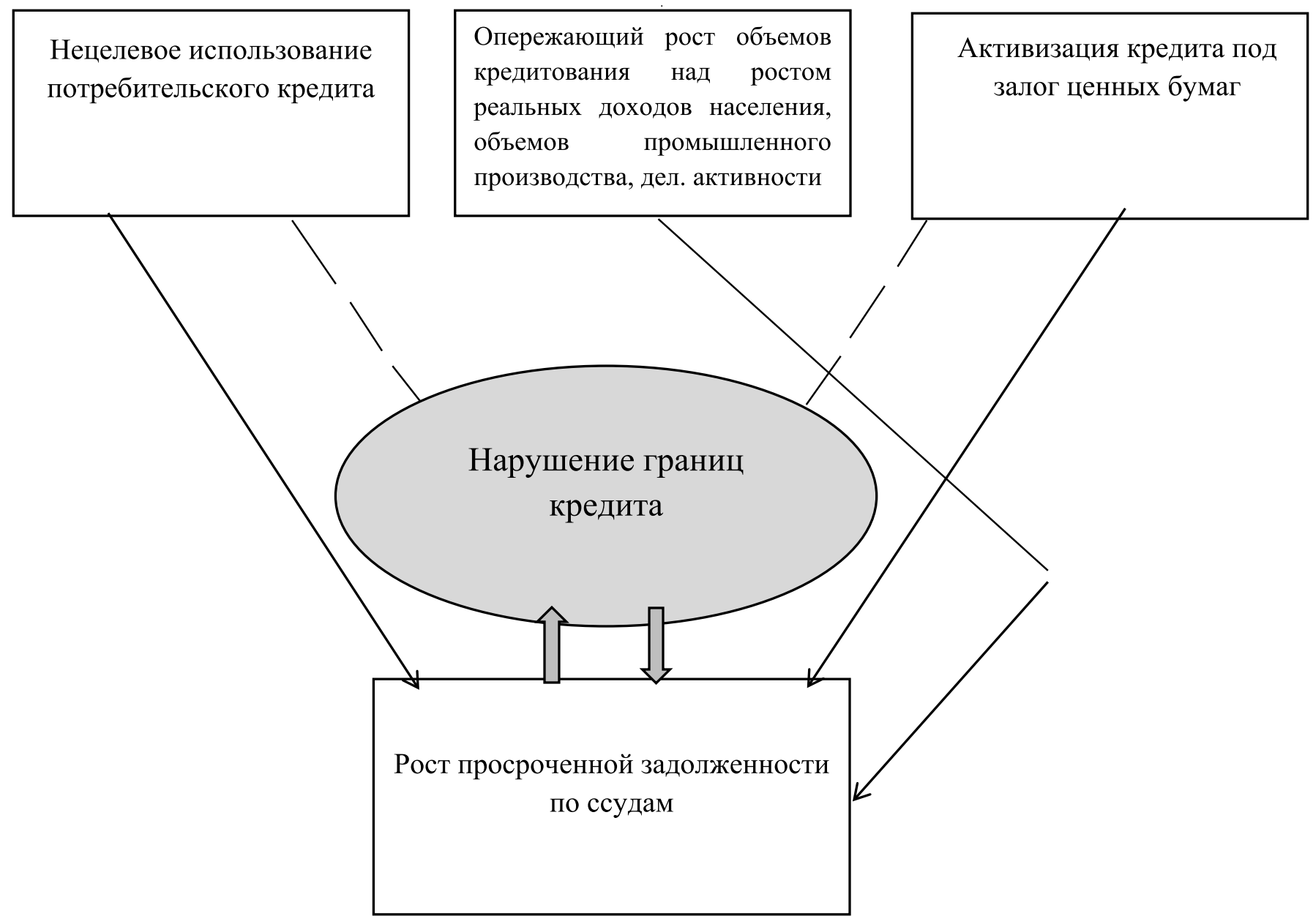

Рис. 1. Факторы нарушения (трансформации) границ кредита и его последствия

теля на 1 июля 2021 г. Всего по итогам I полугодия 2021 г. было выдано 7,62 млн. потребительских кредитов, что на 13,9\% больше по сравнению с аналогичным периодом прошлого года (в 1 полугодии 2020 г.- 6,69 млн. ед.). Тенденция не может не вызывать опасения с учетом текущего состояния макроэкономической среды.

Растет также значение показателя долговой нагрузки населения: во 2-м квартале 2021 г. его среднее значение для потребительских кредитов достигло 61,1\%, увеличившись на 0,4 п.п. по сравнению с 1-м кварталом. По данным Росстата, кредиты физическим лицам в пандемийный год выросли на 13,5\% [2].

Что касается динамики доходов, то, если не учитывать кратковременные околонулевые колебания, реальные доходы населения падают 8-й год подряд. Согласно прогноза Минэкономразвития, реальные располагаемые доходы россиян по итогам 2021 г. не восстановятся до докризисного уровня: они вырастут только на 2,5\% (вместо ожидаемых ранее 3,0\%) после падения на 2,8\% в 2020 году [3]. Ухудшение прогноза по реальным доходам связано в основном с корректировкой ведомством оценки инфляции на конец года на 1,6 п.п. вверх, до 7,4\%, с прогнозируемых ранее 5,8\%.

Еще более пессимистичным оказался прогноз экономистов Национального рейтингового агентства по их мнению, реальные располагаемые доходы населения в 2021 г. окажутся в диапазоне от минус $2 \%$ до 0 [4].

Согласно данным БКИ «Эквифакс» по состоянию на 1 октября 2021 года каждый 10-й потребительский кредит, выданный банком физическому лицу, являлся проблемным, то есть не обслуживался в течение 90 и более дней. В абсолютном значении более 7,1 млн. кредитов находится на данный период в стадии дефолта: это на $3 \%$ выше показателя начала года. Объем просроченной задолженности приближается к 1 трлн. руб., что на 9,2\% выше, чем на начало года [5].

Ускоренный рост необеспеченного потребительского кредитования на фоне сворачивания ограничи- 
тельных противопандемийных мер, не сопровождающийся адекватным ростом доходов и притоком новых заемщиков, ведет к накоплению банками рисков невозврата (к началу осени 2021 г. доля удовлетворенных заявок на необеспеченные кредиты упала по сравнению с августом до 35,1\% или на 1,7 п.п.), свидетельствуя о нарушении границ кредитования.

Помимо нецелевого использования потребительских кредитов, чрезмерного их роста относительно роста реальных доходов населения, причиной нарушения границ кредита является увеличение объемов кредитования, не подкрепленное расширением производства, ростом деловой активности, а также активизация кредитования под залог ценных бумаг (рис. 1). По заявлению главы Минэкономразвития М. Решетникова, «темпы роста ВВП РФ в 2021 г. вряд ли превысят 4,2\%, в сентябре-октябре наблюдается замедление деловой активности на фоне исчерпания восстановления экономики. Ухудшилась эпидемиологическая ситуация...» [6].

С экономической точки зрения границы кредита это верхний рубеж выдачи, лимит ресурсов кредита, та черта, при пересечении которой кредит перестает проявлять свои положительные качества, распадается как экономический феномен.

Известно, что на микроуровне существенной характеристикой границ конкретных ссуд служит их трактовка с позиций заемщика и кредитора. Границы кредита для заемщика зависят от его потребности в заемных средствах, связанной со спецификой бизнеса. Эти границы имеют качественный и количественный характер. Если качественная граница кредита - это кредитоспособность заемщика как гарантия своевременного возврата кредита, то количественная - установленный банком лимит кредитования.

На макроуровне причинами нарушения границ кредита являются экономическая нестабильность, дефицит бюджета, нарушения в сфере обращения и др. Методами преодоления указанных нарушений служат проведение регулятором взвешенной денежно-кредитной политики, проведение денежных и кредитных реформ, конверсия кредитной задолженности др.

Несоблюдение границ кредита, закредитованность заемщика негативно влияет на цены, формирует кредитный пузырь, затрудняет своевременный возврат ссуды.

Исследование проблем границ кредита в отечественной литературе имеет свою историю. Еще в 1931 г. И.А. Трахтенберг писал, что «...границы банковского кредита определяются специфическими закономерностями банковской деятельности, которые в свою очередь обусловливаются закономерностями движения реального капитала» [7]. Объективный характер границ кредита отмечал и Э.Я. Брегель: «В действительности банковский кредит имеет определенные объективные границы... Поскольку кредит предоставляется за счет аккумулируемых банками денежных капиталов и доходов, он ограничен их размерами ...» [8]. Современные авторы отмечают связь границы кредита с материальным производством [9], подчеркивая, в частности, что качественной границей кредита на микроуровне является недостаточная кредитоспособность заемщика [10], а количественной (в узком понимании) - лимит кредитования [10][11].

По мнению О.И. Лаврушина, «...границы кредитования лежат в соблюдении его сущности как возвратного движения ссуженной стоимости, они не могут не существовать, если общество правильно определило его сущность и умеет управлять денежно-кредитными потоками» [12]. Аналогичной позиции придерживаются и другие авторы, отмечая, что границы кредита определяются его законами, как общими, так и частными; к последним относится закон возвратности средств...» [13].

Обобщение теории вопроса и практики современного кредитования позволяет сделать вывод о том, что какие бы ни были границы кредита, и каковы бы ни были факторы, влияющие на них, - доминантой, «лакмусовой бумажкой» их соблюдения на макро- и микроуровне является проявление сущнности кредита как возвратного движения ссуженной стоимости. Соответственно решающим индикатором соблюдения границ банковского кредита на выходе является его возвратность, а на входе - факторы, влияющие на ее соблюдение.

Если говорить о динамике корпоративного кредитования в России, то объем выданных ссуд в первой половине 2021 г. увеличился: в июле он составил 8,27 трлн. руб., что на 10\% больше, чем годом ранее. При этом задолженность по кредитам на 01.08.2021 г. была равна 39,95 трлн. руб., за год практически не изменившись, как и размер просроченной задолженности - 2,7 трлн. руб. или 6,9\% от кредитного портфеля (на конец 2020 г.- 7,1\%; при этом следует отметить, что по итогам 2020 г. просроченная задолженность заемщиков малого и среднего бизнеса выросла на 13\%).

Риски для банковского сектора сохраняются в связи с повышенной неопределенностью в отношении дальнейшего возможного распространения пандемии COVID-19, неустойчивым характером восстановления корпоративного сектора. Одним из главных потенци- 
альных рисков для российской банковской системы, по мнению экспертов (наряду со все более активным участием в непрофильном бизнесе и волатильностью процентных ставок), является ухудшение качества кредитного портфеля юридических лии, которое обычно настигает банки через год после наступления турбулентности. По словам главы АКРА М. Сухова, «существует вероятность того, что платежеспособность заемщиков, кредиты которым были реструктурированы в 2020 году, не восстановится до уровня, достаточного для выполнения обязательств в полном объеме» [14].

Как отметила глава Банка России Э. Набиуллина, такие «скрытые проблемы в будущем могут стать источником системных рисков» [15]. Они связаны с тем, что 40\% реструктурированных кредитов с начала пандемии для поддержки заемщиков (на сумму более 7 трлн. руб. или около $12 \%$ всего кредитного портфеля), по оценке ЦБ РФ - проблемные.

Как отмечалось выше, на выходе определяющим индикатором соблюдения границ банковского кредита является его возвратность, а на входе - факторы, влияющие на ее соблюдение. Среди таких факторов на макроуровне следует выделить спектр инструментов и методов регулирования границ кредита, применяемый Банком России в рамках реализации ДКП:

- обязательные нормативы, включая нормативы кредитных рисков;

- требования к резервам по ссудам и к капиталу;

- административные ограничения;

- квоты и лимиты;

- политика процентных ставок;

- политика рефинансирования и абсорбирования ликвидности;

- операции с иностранной валютой и государственными бумагами и др.

На микроуровне факторами обеспечения своевременной возвратности корпоративного кредита являются:

- наличие ресурсов и желание банка кредитовать исходя из принципов его кредитной политики;

- качество обеспечения;

- соблюдение соответствующих экономических нормативов Банка России;

- уровень оценки кредитоспособности заемщика;

- установление лимитов кредитования (количественная граница кредита)

- расчет рейтинга заемщика.

Многие авторы в своих исследованиях отмечают недостатки в организации в коммерческих банках кредитного процесса, не отвечающего в должной мере на вызовы, о которых говорилось выше. В частности, указывается на отсутствие новых методик расчета лимитов кредитования на заемщика и группу, на кредитный продукт/продукты в целом, построения иерархии лимитов. А поскольку лимит кредитования, как отмечалось выше, является количественной границей кредита со стороны кредитора, представляет интерес изучение опыта ведущих кредитных организаций в части построения эффективного механизма лимитирования сделок, реализуемого в рамках кредитного процесса в целях улучшения качества корпоративного ссудного портфеля - индикатора соблюдения/несоблюдения границ кредитования.

Специально разработанная технология позволяет рассчитать и установить на каждого клиента обоснованный лимит риска. При этом, как показывает практика, совокупность кредитных лимитов, построенных по принципу иерархии, дает возможность, во-первых, обеспечить дополнительный контроль рисков, во-вторых, сократить сроки процесса выдачи ссуды, в-третьих, упростить одобрение новых сделок с заемщиком в будущем [16].

Узловые правила лимитирования заключаются В том, что:

- все сделки происходят в рамках рассчитанных лимитов. При этом продуктовый лимит (разовой ссуды, кредитной линии, «овердрафта» и др.) утверждается одновременно с согласием на сделку;

- определяются ступени субординации лимитов и тип лимита: на клиента, группу взаимосвязанных заемщиков, клиентского менеджера и т.д.;

- сумма лимита, как правило, превышает заявленную потенциальным клиентом; это делается для того, чтобы в дальнейшем кредитовать, во-первых, в рамках ранее установленного лимита, во-вторых, в упрощенном формате (в формате «шесть глаз» или «четыре глаза», с сокращенной кредитной заявкой и т.п.).

Сумма продуктовых лимитов в рассматриваемой системе лимитирования формирует совокупныци лимит кредитования, который устанавливается на базе определения расчетного маркера кредитоемкости исходя из качества предлагаемого обеспечения, величины оборотного капитала заемщика, его способности качественно обслуживать долг, объема высоколиквидных активов, ежемесячной/ежеквартальной выручки, значения EBITDA, рейтинга и др. В рамках совокупного лимита происходят операции, объем которых ограничен суммой продуктовых лимитов на заемщика.

Весь процесс лимитирования основан на организации четкого взаимодействия подразделений и состоит 
Таблица 1. Лимитирование кредитной сделки

\begin{tabular}{|c|c|c|c|}
\hline \multicolumn{4}{|l|}{$\begin{array}{l}\text { Инициирование лимитов } \\
\text { (кредитное подразделение) }\end{array}$} \\
\hline Анализ потребностей заемщика & $\begin{array}{l}\text { Анализ долговой нагрузки } \\
\text { на заемщика }\end{array}$ & $\begin{array}{l}\text { Анализ текущего } \\
\text { использования лимитов }\end{array}$ & $\begin{array}{l}\text { Формулирование запроса } \\
\text { на лимит }\end{array}$ \\
\hline $\begin{array}{l}\text { КИ совместно с КМ изучает } \\
\text { потребности клиента } \\
\text { в банковских продуктах, } \\
\text { фиксирует их в сумме } \\
\text { продуктового лимита }\end{array}$ & $\begin{array}{l}\text { Расчет отношения суммы } \\
\text { ежемесячного платежа к сумме } \\
\text { основного долга }\end{array}$ & $\begin{array}{l}\text { КИ изучает вопрос } \\
\text { о необходимости открытия } \\
\text { дополнительных продуктовых } \\
\text { лимитов }\end{array}$ & $\begin{array}{l}\text { Пакет документов } \\
\text { передается на независимую } \\
\text { экспертизу андеррайтеру }\end{array}$ \\
\hline $\begin{array}{l}\text { Утверждение главных } \\
\text { параметров лимитов }\end{array}$ & $\begin{array}{l}\text { Передача лимитов } \\
\text { на использование }\end{array}$ & Фиксация параметров лимитов & \\
\hline $\begin{array}{l}\text { Утверждение лимитов и их } \\
\text { параметров осуществляется } \\
\text { после их рассмотрения } \\
\text { и корректировки } \\
\text { андеррайтером }\end{array}$ & $\begin{array}{l}\text { Для продуктовых } \\
\text { лимитов должно быть } \\
\text { определено подразделение, } \\
\text { уполномоченное } \\
\text { самостоятельно принимать } \\
\text { решения в формате «6 глаз» }\end{array}$ & $\begin{array}{l}\text { КИ вносит лимиты и их } \\
\text { параметры в проект решения }\end{array}$ & \\
\hline \multicolumn{4}{|l|}{$\begin{array}{l}\text { Использование лимитов } \\
\text { (бизнес-подразделение } \\
\text { и андеррайтер) }\end{array}$} \\
\hline Запрос заемщика & Подготовка заявки и моделей & Утверждение сделки & \\
\hline $\begin{array}{l}\text { Если КИ и КМ корректно } \\
\text { оценили потребности } \\
\text { заемщика, то его новые запросы } \\
\text { на банковские продукты } \\
\text { будут укладываться в рамки } \\
\text { одобренных продуктовых } \\
\text { лимитов }\end{array}$ & $\begin{array}{l}\text { При кредитовании в рамках } \\
\text { лимитов запрос на новые } \\
\text { лимиты (любого уровня } \\
\text { иерархии) не производится, } \\
\text { что сокращает объемы анализа } \\
\text { заявки со стороны андеррайтера }\end{array}$ & $\begin{array}{l}\text { Если продуктовый лимит был } \\
\text { передан на использование, } \\
\text { то решение о выдаче ссуды } \\
\text { принимает уполномоченное } \\
\text { подразделение в формате «6 } \\
\text { глаз» }\end{array}$ & \\
\hline $\begin{array}{l}\text { Если запрос клиента } \\
\text { укладывается в рамки } \\
\text { одобренных продуктовых } \\
\text { лимитов, то кредитование } \\
\text { происходит в рамках лимита. } \\
\text { Заемщик в этом случае } \\
\text { предоставляет сокращенный } \\
\text { пакет документов }\end{array}$ & & & \\
\hline
\end{tabular}

КИ - кредитный инспектор
КМ - клиентский менеджер

из трех этапов: инициирование лимитов, утверждение лимитов, использование лимитов (см. табл. 1).

В качестве резюме следует отметить, что признание лимита кредитования со стороны банка в качестве количественной граница кредита подчеркивает важность совершенствования лимитирования в рамках каждой кредитной сделки. Инструменты такого лимитирова- ния - иерархический принцип их построения (совокупный и продуктовые лимиты), ступени субординации, многофакторный расчетный маркер кредитоемкости и др. на фоне четкой организации взаимодействия заинтересованных подразделений. Практическое значение полученных результатов состоит в применении широким кругом банков перспективного механизма лимитирования сделок. 


\section{ЛИТЕРАТУРА}

1. Пирамида в кредит. [Электронный ресурc]. URL: https://www.kommersant.ru/doc/4929561. 06.08.2021.

2. Жизнь взаймы - россияне берут рекордные кредиты. [Электронный ресурc]. URL: https://www.finam.ru/analysis/newsitem/zhizn-vzaiymy-rossiyaneberut-rekordnye-kredity-20210506-202249/06.05.2021.

3. Минэк не ждет восстановления доходов россиян в 2021 году. [Электронный ресурc]. URL: https://iz.ru/1236941/2021-10-18/minek-ne-zhdetvosstanovleniia-dokhodov-rossiian-v-2021-godu. 18.10.2021 (дата обращения: 18.10.2021).

4. Экономисты спрогнозировали рост доходов россиян на 1,6\%. [Электронный ресурс]. URL: https://news.rambler.ru/sociology/47406908-ekonomistysprognozirovali-rost-dohodov-rossiyan-na-1-6 (дата обращения: 18.10.2021).

5. «Эквифакс»: каждый десятый потребительский кредит просрочен. [Электронный ресурс]. URL: https://www.banki.ru/news/lenta/?id=10955367 (дата обращения: 25.10.2021).

6. Официальный сайт «Интерфакс». [Электронный ресурс]. URL: https://www.interfax.ru/business/797841. 18.10.2021.

7. Трахтенберг И.А. Современный кредит и его организация. Изд. 2-е. М.: 0ГИЗ. - 1931. - 222 стр.

8. Брегель Э.Я. Кредит и кредитная система капитализма. М.: Госфиниздат. - 1948. - 672 стр.

9. Мазурина Т.Ю. Экономическая природа и границы банковского инвестиционного кредита // Вестник университета. — 2013. — № 4. — С. 132-139.

10. Семенов С.К. 0 границе кредитования // Финансы и кредит. — N21 (135). — 2003. - N21(135). — C. 17-22.

11. Костерина Т.М., Панова Т.А. Методологические основы анализа границ кредита // Финансы и кредит. — 2015. — N32.—C. 26-38.

12. Лаврушин 0.И. Базовые основы кредита и его использование в современной экономике // Journal of Economic Regulation (Вопросы регулирования экономики). - 2017. - N8.-C. 1-10.

13. Валенцева Н.И., Ларионова И.В., Кудрявцева Ю.В. Теоретические основы экономических границ кредита и развития потребительского кредитования // Банковские услуги. - 2011. - № 1.—C. 2-11.

14. АКРА назвало три главных риска банковской системы [Электронный ресурс]. URL: https://ria.ru/20210531/banki-1734861221. Риа Новости. 31.05.2021.

15. URL: https://www.finam.ru/analysis/newsitem/vyxod-iz-regulyatornyx-poslableniiy-dlya-bankov-dolzhen-proizoiyti-s-1-iyulya-20210218-11450/.

16. Ушанов А.Е. Оптимизация кредитного процесса в условиях вызовов // Финансы и кредит. — 2015.— N21.—C. 38-41.

17. URL: https://www.finam.ru/analysis/newsitem/vyxod-iz-regulyatornyx-poslableniiy-dlya-bankov-dolzhen-proizoiyti-s-1-iyulya-20210218-11450/

18. Ushanov A.E. Optimization of the credit process in the conditions of challenges // Finance and credit. — 2015. — N21. - pp. 38-41.

(с Ушанов Александр Евгеньевич ( ushanov_0656@mail.ru ).

Журнал «Современная наука: актуальные проблемы теории и практики»

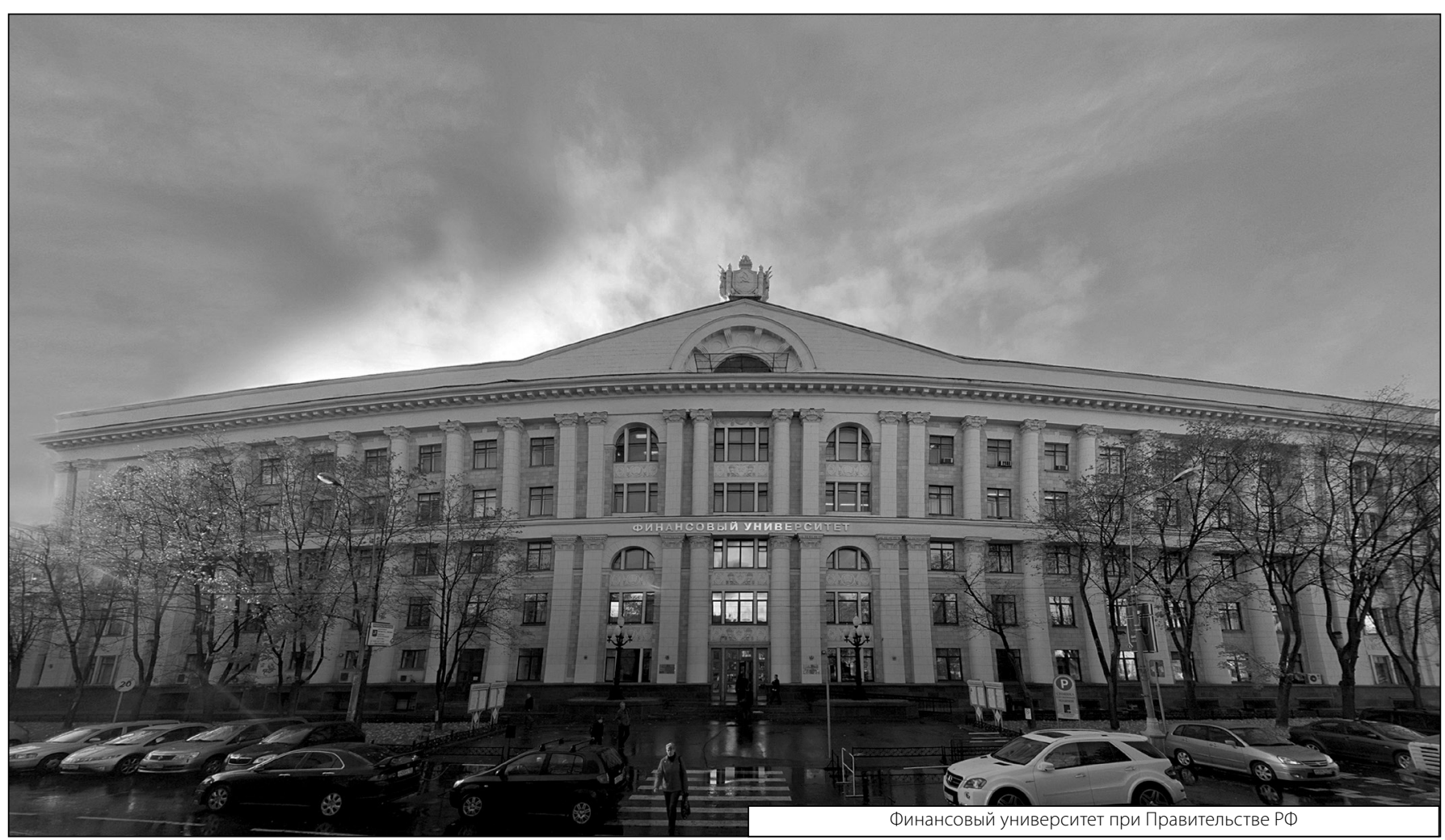

